\title{
A new species of Afrobaetodes (Ephemeroptera : Baetidae) and first report of this genus from Madagascar
}

\author{
J.-L. Gattolliat ${ }^{1}$ \\ M. Sartori ${ }^{1}$
}

Keywords : Ephemeroptera, Baetidae, Afrobaetodes, new species, Madagascar.

Afrobaetodes lenae n. sp. is described at the larval stage. It represents the first report of Afrobaetodes in Madagascar and outside continental Africa. The species presents all the very peculiar apomorphies of Afrobaetodes. It is distinguished from the African species by the absence of tracheation on the abdominal gills and the absence of compact tufts of stout setae on the pronotum.

Affinities and ecology are discussed.

Une nouvelle espèce d'Afrobaetodes (Ephemeroptera : Baetidae) et première mention du genre à Madagascar.

Mots-clés : Ephemeroptera, Baetidae, Afrobaetodes, nouvelle espèce, Madagascar.

Afrobaetodes lenae n. sp. est décrit au stade larvaire. Il s'agit de la première mention du genre Afrobaetodes à Madagascar et hors d'Afrique continentale. Cette espèce présente toutes les apomorphies des Afrobaetodes. Elle se distingue des autres espèces du genre par l'absence de trachéation des branchies abdominales et l'absence de groupes compacts de soies sur le pronotum.

Les affinités et l'écologie de cette espèce sont discutées.

\section{Introduction}

The genus Afrobaetodes has been erected by Demoulin (1970) for an unnamed larva described by Kimmins (1955). This genus differs from all other baetid genera in having a gill proceeding from the tip of the first segment of the labial palp, a pair of filamentous gills arising from the prosternum and the gill lamellae inserted on the ventral face of the abdomen (Kimmins 1955, Gillies 1991b). It presents similar adaptations with the American Baetodes complex (Lugo-Ortiz \& McCafferty 1996).

Afrobaetodes actually involves four African species: A. berneri Demoulin (type species), A. delicatissimus (Barnard), A. pugio Gillies and A. pusillus (Navas).

1. Museum of Zoology, P.O. Box 448, CH-1000 Lausanne 17, Switzerland.

E-mail: Jean-Luc.Gattolliat@ie-zea.unil.ch
The distinction between $A$. delicatissimus and $A$. berneri remains doubtful ; it is only based on the presence or absence of hindwing (Gillies 1991b).

Herein, we report for the first time the genus Afrobaetodes in Madagascar, based on a new species described at the larval stage. This discovery greatly enlarges the distribution of Afrobaetodes, until now restricted to Eastern Africa.

The holotype and part of the paratypes are housed in the Museum of Zoology, Lausanne, Switzerland. Other paratypes are deposited in the Museum National d'Histoire Naturelle, Paris.

\section{Afrobaetodes lenae Gattolliat \& Sartori n. sp}

\section{Larva :}

Maximal length (full grown specimen) : Body 5.2 $\mathrm{mm}$. Cerci $4.7 \mathrm{~mm}$. Terminal filament : reduced to a single segment. 


\section{- Head}

Coloration brown with darker pattern (Fig. 9). Antennae pale yellowish brown. Eyes black; turbinate eyes brown, ocelli grey.

Labrum (Fig. 1) with an anteromedial emargination, dorsally with a row of about 8 setae, very different in size, laterally and proximally with small setae ; apical margin bordered with setae, few of them furcated ; ventrally without a subparallel to the lateral margin row of very small setae.

Hypopharynx as in figure 6 ; lingua shorter than superlingua, covered with thin setae but without bristle tuft at the apex.

Right mandible (Fig. 2) with two sets of incisors ; prostheca long and thin, apically bifid (Fig. 3) ; welldeveloped tuft of setae between prostheca and mola ; tuft of setae at the apex of the mola reduced to three setae ; basal half with dorsally short thin setae.

Left mandible (Fig. 4) with incisors almost fused; prostheca well-developed, with 4 teeth together with a comb-shaped structure (Fig. 5) ; tuft of setae between prostheca and mola well-developed ; no tuft of setae at the apex of the mola ; basal half with dorsally short thin and also broader setae.

Maxillae (Fig. 8) with 4 teeth, the distal one opposed to the three others ; row of few broad single setae ending with a tuft of long setae ; pectined or spine-like setae absent ; set of 5 to 6 setae at the basis of the galea, not arranged in a row ; 1 single seta perpendicularly to the margin of the galea ; palp 2-segmented, weakly chitinised, shorter than the galealacinia ; gill proceeding from the tip of the basal segment.

Labium (Fig. 7) with glossae subequal to paraglossae ; inner margin of the glossae apically with stout setae, outer margin almost without stout setae, no setae on the ventral side ; paraglossae stout, apically rounded, with simple setae apically and on the outer margin. Labial palp 3-segmented ; first segment stout, as long as the second and third combined, dorsally with micropores; second segment moderately produced apicomedially, row of 5 setae, outer margin with few thin setae ; third segment subconical, covered apically with short setae.

\section{- Thorax}

Coloration light brown with medium to dark brown markings on the pronotum (Fig. 9).

Hindwing pad present.

Two additionnal gills arising from the prosternum (Fig. 10).
Legs coloration : femora light brown, apically darker ; tibiae and tarsi middle brown (Fig. 9).

Forelegs (Fig. 15), coxa with only few minute setae.

Femora with dorsally a row of long setae, becoming double to triple toward the apex, apical patch of stout setae absent ; few long and thin setae on the apical margin ; without other setae on the lateral margin ; ventral margin with only few minute acute setae.

Tibiae with very scarce minute or long and thin setae dorsally ; few short and pointed setae on the ventral margin.

Tarsi almost without setae dorsally ; few short and pointed setae on the ventral margin ; tarsal claws (Fig. 16) with 2 rows of teeth, the first one formed by about 8 subequal teeth, the second one reduced to two lateral teeth (a single tooth on the second and third pair of legs) in a lateral position ; a single subapical, long and thin seta.

Second and third legs similar to foreleg except by the second row of teeth of the claws formed by a single tooth.

\section{- Abdomen}

Coloration light to dark brown (Fig. 9), not very contrasted, very variable among the examined population. Abdomen laterally flattened. Line of median minute tubercles on terga 1 to 8 .

Terga (Fig. 11) shagreen, without scale bases or insertion traces of setae ; posterior margin smooth without spines ; row of bifid or trifid spines subparallel to the margin.

Sterna (Fig. 12) almost smooth with numerous broad and long setae and few thin and long ones ; smooth posterior margin without spines.

Smooth gills in ventral position on abdominal segments 1 to 6 , neither tracheated, nor serrated at the apex, covered with micropores (Fig. 13).

Paraproct (Fig. 14) without spines on the distal margin ; surface covered with numerous scales ; few thin setae randomly distributed, broad setae near the margin ; postero-lateral extension distally covered with scales, without spines on the distal margin.

Cerci coloration brown, with short and thin setae on the inner margin ; median caudal filament reduced to a single segment.

\section{Male and female imagoes : Unknown.}

\section{Material examined :}

Holotype : one larva P0403, Prospection, 20.4.1995, Madagascar, Mandrare Basin, Sakamamba river, locality Imanombo, Long. $45^{\circ} 45^{\prime} 59^{\prime \prime} \mathrm{E}$, Lat. $24^{\circ} 28^{\prime} 32^{\prime \prime} \mathrm{S}$, Altitude $340 \mathrm{~m}$. J-M Elouard and M. Sartori. 

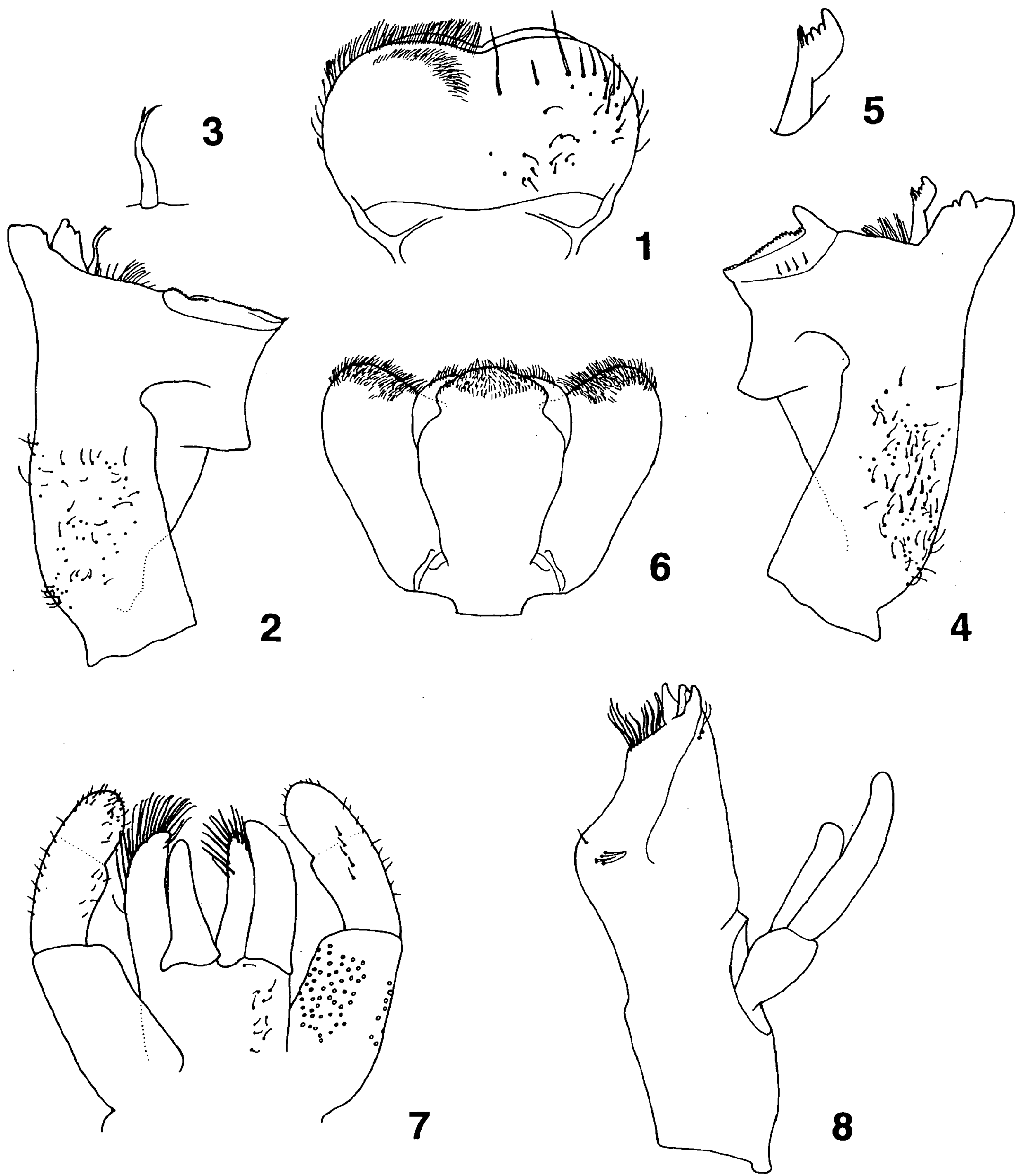

Figs 1 to 8 . Mouthparts of $A$. lenae : 1 : labrum. (left : ventral ; right : dorsal). $2:$ right mandible. $3:$ right prostheca. $4:$ left mandible. $5:$ left prostheca. $6:$ hypopharynx. $7:$ labium $8:$ left maxilla.

Figs 1 à 8 . Structures larvaires de $A$. lenae : 1 : labre (gauche : ventral; droite : dorsal). $2:$ mandibule droite. $3:$ prosthéca droite $4:$ mandibule gauche. $5:$ prosthéca gauche. $6:$ hypopharynx. $7:$ labium. $8:$ maxille gauche. 
Paratypes: 35 larvae, same data as holotype.

Etymology : This species is dedicated to Lena Brunner.

\section{Discussion}

Demoulin (1970) roughly described the genus Afrobaetodes. Despite the peculiarity of the larvae, he was not able to put in advance clear apomorphies to distinguish it from other baetid genera. Its diagnosis was

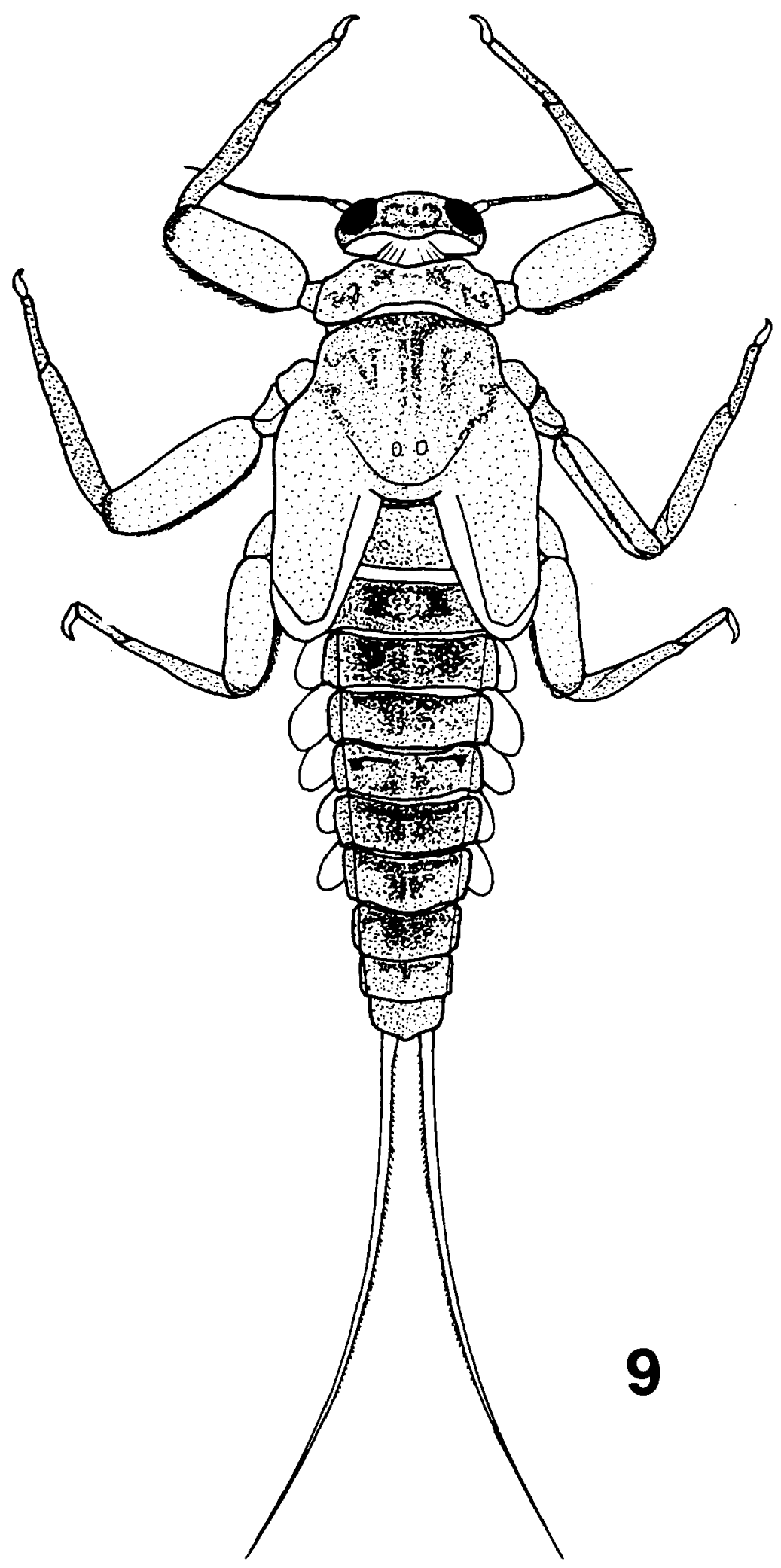

Fig. 9. Larva of $A$. lenae : in toto, dorsal view.

Fig. 9. Larve de $A$. lenae : in toto, vue dorsale. greatly improved afterwards especially by the description of new species and the imaginal stages (Gillies $1979,1991 \mathrm{~b}$ ). The genus Afrobaetodes is now clearly defined by the following apomorphies : at the larval stage by a gill proceeding from the tip of the first segment of the labial palp, a pair of filamentous gills arising from the prosternum, the gill lamellae inserted on the ventral face of the abdomen, tarsal claws with a double row of teeth, the second one generally reduced to one or two teeth (Kimmins 1955, Gillies 1991b) and at the imaginal stage by a forewing with a single reduced intercalary vein and the first segment of male genital forceps with a well-developed apophysis (Gillies 1979, 1991b).

The phylogenetic position of Afrobaetodes is difficult to establish because the genus presents high adaptation: It presents similarities with the genus Acanthiops Waltz and McCafferty such as median caudal filament reduced to a single segment, tarsal claws with a double row of teeth (Waltz \& McCafferty 1987). But none of the typical apomorphies of Afrobaetodes especially the non-abdominal gills are present in Acanthiops or any other African genera.

Afrobaetodes shares with the genus Baetodes Needham and Murphy some important features such as adaptations to shallow fast water, additionnal gills arising from the prosternum, abdominal gills in a ventral position, first segment of male genital forceps with a well-developed apophysis (Lugo-Ortiz \& McCafferty 1996). But Afrobaetodes and Baetodes present differences in the following features : number of rows of teeth on the larval claws, presence-absence of setae between prostheca and mola, and number of intercalary veins. Such features are used to distinguish the major lineages in the baetid family (Gillies 1991a). Of course, some of these features can secondarily evolve, as for instance the reduction in the number of intercalary veins by Cloeodes in Africa (Gattolliat \& Sartori submitted). But the simultaneous divergence of all these features clearly indicates that Afrobaetodes and Baetodes belong to different lineages.

The subapical setae on the lateral margin of the tarsal claws is a clear synapomorphy of the Baetodes complex which is not shared with Afrobaetodes. On the other hand, Afrobaetodes owns unique apomorphical features such as gill proceeding from the tip of the first segment of the maxillary palp.

The primitive genera of the Baetodes complex such as Mayobaetis Waltz and McCafferty and Prebaetodes Lugo-Ortiz and McCafferty do not possess additionnal gills arising from the prosternum but still have subapical setae on the lateral margin of the tarsal claws 
(Waltz \& McCafferty 1985) and Afrobaetodes owns these kind of gills but have subapical setae in the usual position (Gillies 1991b). Consequently, the presence of additionnal gills arising from the prosternum by Afrobaetodes and Baetodes must be considered as convergency or the Baetodes complex is polyphyletic.

A. lenae presents all the apomorphical features of the genus Afrobaetodes. However, it differs from the other African species by the absence of tracheation on the abdominal gills, the shape of the coxal spurs of legs 1 to 3 and the presence of a line of median minute tubercles down the dorsum of the abdomen (which is well-developed by $A$. pugio and absent in the other species). Moreover, it differs from A. pugio by the absence of compact tuft of stout setae on the pronotum (Gillies 1991b).

Despite the extensive collect of material in almost all the main basins of Madagascar, $A$. lenae has been found only in a single locality. This species occurs in quite shallow waters with rounded stones. Despite the presence of numerous ready to moult larvae, no imago has been caught by light-traps. The ecology of this species is quite similar to that of $A$. pugio which lives in the shallow over flow on the top of stones. The imagoes were supposed to have diurnal activities which may explain why they were not caught by light-traps (Gillies 1991b).

\section{Acknowledgements}

We thank the whole team of the Laboratoire de Recherche sur les Systèmes Aquatiques et leur Environnement (LRSAE) and especially its director Dr. J.-M. Elouard, for logistical assistance, great help during field work in Madagascar and for donation of specimens.

\section{References}

Demoulin G. 1970. - Ephemeroptera des faunes éthiopiennes et malgaches. S. Afr. Anim. Life, $14: 24-170$.

Gillies M.T. 1979. - Cloeon pusillum Navàs, a species of Afrobaetodes Demoulin (Ephemeroptera: Baetidae). Ent. mon. Mag., $114: 153-154$

Gillies M.T. 1991a. - A diphyletic origin for the two-tailed baetid nymphs occuring in East African stony streams with description of the new genus and species Tanzaniella spinosa gen. nov. sp. nov. In J. Alba-Tercedor \& A. Sanchez-Ortega (Eds.), Overview and strategies of Ephemeroptera and Plecoptera : 175-181. The Sand Crane Press, Inc.

Gillies M.T. 1991b. - New records and a new species of Afrobaetodes Demoulin (Baetidae : Ephemeroptera) from Tanzania. Rev. Hydrobiol. trop., 24 (2) : 105-110.

Kimmins D.E. 1955. - Ephemeroptera from Nyasaland with description of three new species and some interesting nymphal forms. Ann. Mag. nat. Hist., $8: 859-880$.

Lugo-Ortiz C.R. \& McCafferty W.P. 1996. - Phylogeny and classification of the Baetodes complex (Ephemeroptera: Baetidae), with description of a new genus. J. N. Am. Benthol. Soc., 15 (3) : 67-380.

Waltz R.D. \& McCafferty W.P. 1985. - Moribaetis : a new genus of Neotropical Baetidae (Ephemeroptera). Proc. Entomol. Soc. Wash., $87: 367-380$.

Waltz R.D. \& McCafferty W.P. 1987. - New genera of Baetidae (Ephemeroptera) from Africa. Proc. Entomol. Soc. Wash., 89 : 95-99. 